\title{
Lung mechanics in type L CoVID-19 pneumonia: a pseudo-normal ARDS
}

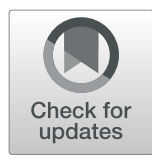

\author{
Lorenzo Viola ${ }^{1 *}$ (D), Emanuele Russo ${ }^{1}$, Marco Benni ${ }^{1}$, Emiliano Gamberini ${ }^{1}$, Alessandro Circelli ${ }^{1}$, Luca Bissoni ${ }^{1}$, \\ Domenico Pietro Santonastaso ${ }^{1}$, Giovanni Scognamiglio', Giuliano Bolondi ${ }^{1}$, Luca Mezzatesta ${ }^{1,2}$ and \\ Vanni Agnoletti ${ }^{1}$
}

\begin{abstract}
Background: This study was conceived to provide systematic data about lung mechanics during early phases of CoVID-19 pneumonia, as long as to explore its variations during prone positioning.

Methods: We enrolled four patients hospitalized in the Intensive Care Unit of "M. Bufalini" hospital, Cesena (Italy); after the positioning of an esophageal balloon, we measured mechanical power, respiratory system and transpulmonary parameters and arterial blood gases every 6 hours, just before decubitus change and 1 hour after prono-supination.

Results: Both respiratory system and transpulmonary compliance and driving pressure confirmed the pseudo-normal respiratory mechanics of early CoVID-19 pneumonia (respectively, $\mathrm{C}_{\mathrm{RS}} 40.8 \mathrm{ml} / \mathrm{cmH}_{2} \mathrm{O}$ and $\mathrm{DP}_{\mathrm{RS}} 9.7 \mathrm{cmH}_{2} \mathrm{O} ; \mathrm{C}_{\mathrm{L}} 53.1 \mathrm{ml} /$ $\mathrm{CmH}_{2} \mathrm{O}$ and $\mathrm{DP}_{\mathrm{L}} 7.9 \mathrm{cmH}_{2} \mathrm{O}$ ). Interestingly, prone positioning involved a worsening in respiratory mechanical properties throughout time ( $\mathrm{C}_{\mathrm{RSSSUP}} 56.3 \mathrm{ml} / \mathrm{cmH}_{2} \mathrm{O}$ and $\mathrm{C}_{\mathrm{RS}, \mathrm{PR}} 41.5 \mathrm{ml} / \mathrm{cmH}_{2} \mathrm{O}-\mathrm{P} 0.37 ; \mathrm{CL}_{\mathrm{LSUP}} 80.8 \mathrm{ml} / \mathrm{cmH}_{2} \mathrm{O}$ and $\mathrm{C}_{\mathrm{L}, \mathrm{PR}} 53.2 \mathrm{ml} /$ $\mathrm{CmH}_{2} \mathrm{O}-\mathrm{P}$ 0.23).
\end{abstract}

Conclusions: Despite the severe ARDS pattern, respiratory system and lung mechanical properties during CoVID-19 pneumonia are pseudo-normal and tend to worsen during pronation.

Trial registration: Restrospectively registered.

Keywords: CoVID-19 pneumonia, transpulmonary pressure, prone positioning, mechanical power.

\section{Background}

Since its outbreak, in January, 2020, it has been clear that CoVID-19 pneumonia is atypical. Despite a full concordance to Berlin criteria for Acute Respiratory Distress Syndrome (ARDS), respiratory system mechanics is preserved [1]. Mechanical ventilation and muscular paralysis are recommended in worsening respiratory insufficiency [2]; in a substantial number of cases, prone positioning significantly improves oxygenation.

Little is known about isolated lung behavior in CoVID-19 pneumonia. Hence, the aim of this study is to analyze lung mechanical properties in the first hours

\footnotetext{
* Correspondence: lorenzo.viola@auslromagna.it

'U.O. Anestesia e Rianimazione, Ospedale "M. Bufalini" Hospital, 286, Viale Ghirotti, Cesena, Italy

Full list of author information is available at the end of the article
}

after the beginning of mechanical ventilation and in prone and supine position.

\section{Methods}

A retrospective observational study was performed at Maurizio Bufalini hospital (Cesena, Italy). Patients hospitalized in the Intensive Care Unit (ICU) from 03/23/ 2020 to $04 / 10 / 2020$ were enrolled. The inclusion criteria were: age $>18$ years, need of mechanical ventilation, need of muscular paralysis and $<48$ hours of tracheal intubation.

After admission in ICU, a naso-gastric tube with an esophageal balloon (Nutrivent ${ }^{\circ}$ - SEDA S.p.A., Mirandola, Italy) was positioned; the correct positioning and insufflation volume were tested with the occlusion method and measures were recorded with a multiparametric monitor

(c) The Author(s). 2020 Open Access This article is licensed under a Creative Commons Attribution 4.0 International License, which permits use, sharing, adaptation, distribution and reproduction in any medium or format, as long as you give appropriate credit to the original author(s) and the source, provide a link to the Creative Commons licence, and indicate if changes were made. The images or other third party material in this article are included in the article's Creative Commons licence, unless indicated otherwise in a credit line to the material. If material is not included in the article's Creative Commons licence and your intended use is not permitted by statutory regulation or exceeds the permitted use, you will need to obtain permission directly from the copyright holder. To view a copy of this licence, visit http://creativecommons.org/licenses/by/4.0/. 
connected to esophageal balloon and ventilator circuit (Optivent ${ }^{\circ}$ - SEDA S.p.A., Mirandola, Italy).

Protective ventilation, defined as tidal volume $\left(\mathrm{V}_{\mathrm{t}}\right)$ of 5-7 $\mathrm{ml} / \mathrm{kg}$ predicted body weight (PBW), was used. Respiratory rate (RR) was set to tolerate mild hypercarbia $\left(\mathrm{p}_{\mathrm{a}} \mathrm{CO}_{2}<60 \mathrm{mmHg}\right)$ and/or $\mathrm{pH}>7.25$.

Measures were performed at admission, then every six hours or just before placing patients in prone or supine position and one hour after the change of decubitus. An arterial blood gas sample was collected along with every evaluation. We stopped measuring when muscular paralysis was suspended. Ventilator settings were recorded; static parameters were obtained through a 3 seconds inspiratory and expiratory hold. Airway $\left(\mathrm{P}_{\mathrm{AW}}\right)$ and esophageal $\left(\mathrm{P}_{\mathrm{ES}}\right)$ pressure values were recorded and the latter was used to calculate transpulmonary pressure $\left(\mathrm{P}_{\mathrm{L}}\right)$, as the result of the real-time subtraction of $\mathrm{P}_{\mathrm{ES}}$ to $\mathrm{P}_{\mathrm{AW}}$. Subsequently, compliance $\left(C_{R S}, C_{L}\right)$, driving pressure $\left(\mathrm{DP}_{\mathrm{RS}}, \mathrm{DP}_{\mathrm{L}}\right)$ and mechanical power $\left(\mathrm{MP}_{\mathrm{RS}}, \mathrm{MP}_{\mathrm{L}}\right)$ related both to respiratory system and lung were calculated [3].

\section{Results}

We report data of four consecutive patients who fulfilled the inclusion criteria; two more patients were enrolled and excluded from the analysis - one died and the other was suspended myoresolution after enrollment. In all patients, chest computed tomography (CT) showed interstitial pneumonia without loss of parenchymal aeration; patients were put on mechanical ventilation within 24 hours of hospital admission. In Table 1 are summarized the main clinical and ventilatory features for every patient.

The median time of observation was 54.5 hours. Patients underwent 1.5 median cycles of prono-supination, for a median pronation time of 17 (IQR 7) hours per cycle. Median $\mathrm{V}_{\mathrm{t}}$ was 5.9 (IQR 0.5) $\mathrm{ml} / \mathrm{kg} \mathrm{PBW}$ and median RR was 20 (IQR 4.8) breaths per minute; $\mathrm{MP}_{\mathrm{RS}}$ was 17.9 (IQR 7.1) $\mathrm{J} / \mathrm{min}$, while $\mathrm{MP}_{\mathrm{L}}$ was $13.1(2.8) \mathrm{J} / \mathrm{min}$. Median $\mathrm{C}_{\mathrm{RS}}$ and $\mathrm{DP}_{\mathrm{RS}}$ were, respectively, 40.8 (IQR 19.4) $\mathrm{ml} / \mathrm{cmH}_{2} \mathrm{O}$ and 9.7 (IQR 4) $\mathrm{cmH}_{2} \mathrm{O}$. The same parameters, calculated using the transpulmonary pressure, led to a median $\mathrm{C}_{\mathrm{L}}$ of 53.1 (IQR 35) $\mathrm{ml} / \mathrm{cmH}_{2} \mathrm{O}$ and a median $\mathrm{DP}_{\mathrm{L}}$ of 7.9 (IQR 3.9) $\mathrm{cmH}_{2} \mathrm{O}$.

The values reported in Table 1 referring to prone and supine position represent the median of all the measurements done during the entire duration of the decubitus, independently of the time passed from decubitus change and the number of pronation cycles performed. No statistically significant variation was observed in respiratory system ( $\mathrm{C}_{\mathrm{RS}, \mathrm{SUP}} 40.9$ (IQR 21.6) $\mathrm{ml} / \mathrm{cmH}_{2} \mathrm{O} ; \mathrm{C}_{\mathrm{RS}, \mathrm{PR}} 40.6$ (IQR 14.1) $\mathrm{ml} / \mathrm{cmH}_{2} \mathrm{O}-\mathrm{P}$ 0.93) and lung $\left(\mathrm{C}_{\mathrm{L}, \mathrm{SUP}} 55.6\right.$ (IQR 35.8) $\mathrm{ml} / \mathrm{cmH}_{2} \mathrm{O} ; \mathrm{C}_{\mathrm{L}, \mathrm{PR}} 48.9$ (IQR 26.2) $\mathrm{ml} / \mathrm{cmH}_{2} \mathrm{O}$ - P 0.7) mechanics during prone positioning.

\section{Discussion}

CoVID-19 pneumonia is peculiar: despite a severe hypoxemia, respiratory system mechanics is pseudo-normal [1]. Gattinoni et al.. described a biphasic trend of the CoVID-19 pneumonia: in the initial phase - type L pneumonia - elastance is low, as well as recruitability, ventilation/perfusion ratio (V/Q ratio) and lung weight on CT scan. Conversely, in the second phase - type $\mathrm{H}$ pneumonia (20-30\% of cases) - elastance, recruitability and lung weight are high and right-to-left shunt predominates $[4,5]$, thus framing in a classical form of ARDS. However, data regarding isolated lung mechanical properties in type $\mathrm{L}$ pneumonia are partial and disorganized.

We present preliminary data of a series of patients affected by type $\mathrm{L}$ pneumonia. Through the systematic evaluation of transpulmonary pressure, our findings seem to confirm the pseudo-normality of lung mechanics during the first days of mechanical ventilation and in different clinical settings. Even if lungs were severely damaged, the transpulmonary pressures remained below the thresholds commonly referred to as harmful [6], confirming a preserved lung aeration.

Another proof of the pseudo-normality of the respiratory system comes from the calculation of mechanical power [3]. Serpa Neto and coworkers found that risk for ventilation-induced lung injury (VILI) starts to increase from a value above $17 \mathrm{~J} / \mathrm{min}$ [7]. Despite high ventilatory requests for maintaining acceptable $\mathrm{p}_{\mathrm{a}} \mathrm{CO}_{2}$ and $\mathrm{pH}$, in our series $\mathrm{MP}_{\mathrm{RS}}$ remained at a borderline value of $17.9 \mathrm{~J} / \mathrm{min}$. In an experimental study, Cressoni et al. found that VILI occurs with a $\mathrm{MP}_{\mathrm{L}}$ above $12 \mathrm{~J} / \mathrm{min}$ [8]; our data show a median $\mathrm{MP}_{\mathrm{L}}$ of $13.1 \mathrm{~J} / \mathrm{min}$, that is slightly above the harmful value. Therefore, while standard protective ventilation is unlikely to lead to VILI, we cannot clearly define whether the ventilatory demands in type $\mathrm{L}$ pneumonia are injurious to the lung.

Type L pneumonia in characterized by a profound hypoxemia, in most cases dramatically responsive to pronation. Prone positioning involves a redistribution of transpulmonary pressure throughout the lung and an inflation improvement in well perfused dorsal areas, leading to an amelioration of ventilation/perfusion ratio (V/Q ratio) [9]. We evaluated the V/Q ratio through alveolar-toarterial oxygen gradient $\left(\mathrm{A}-\mathrm{aO}_{2}\right.$ gradient $)$ and end-tidal $\mathrm{CO}_{2} / \mathrm{p}_{\mathrm{a}} \mathrm{CO}_{2}$ ratio ( $\mathrm{EtCO} / \mathrm{p}_{\mathrm{a}} \mathrm{CO}_{2}$ ratio) $[5,10]$ both in prone and supine positioning, just before the decubitus change. As expected, pronation entails a reduction of $\mathrm{V} / \mathrm{Q}$ mismatch $\left(\mathrm{A}-\mathrm{aO}_{2}\right.$ gradient $_{\mathrm{SUP}} 419 \mathrm{mmHg} ; \mathrm{A}-\mathrm{aO}_{2}$ gradient $_{\mathrm{PR}} 310 \mathrm{mmHg}-\mathrm{P}$ 0.29; $\mathrm{EtCO}_{2} / \mathrm{p}_{\mathrm{a}} \mathrm{CO}_{2}$ ratio SUP $_{\text {0.6 }}$ 0.6; $\mathrm{EtCO}_{2} / \mathrm{p}_{\mathrm{a}} \mathrm{CO}_{2}$ ratio $\mathrm{PR} 0.71-\mathrm{P}$ 0.63). Interesting data come from the analysis of the last measurements done before the variation of the positioning, which account for the extreme consequences of prone vs. supine positioning; 


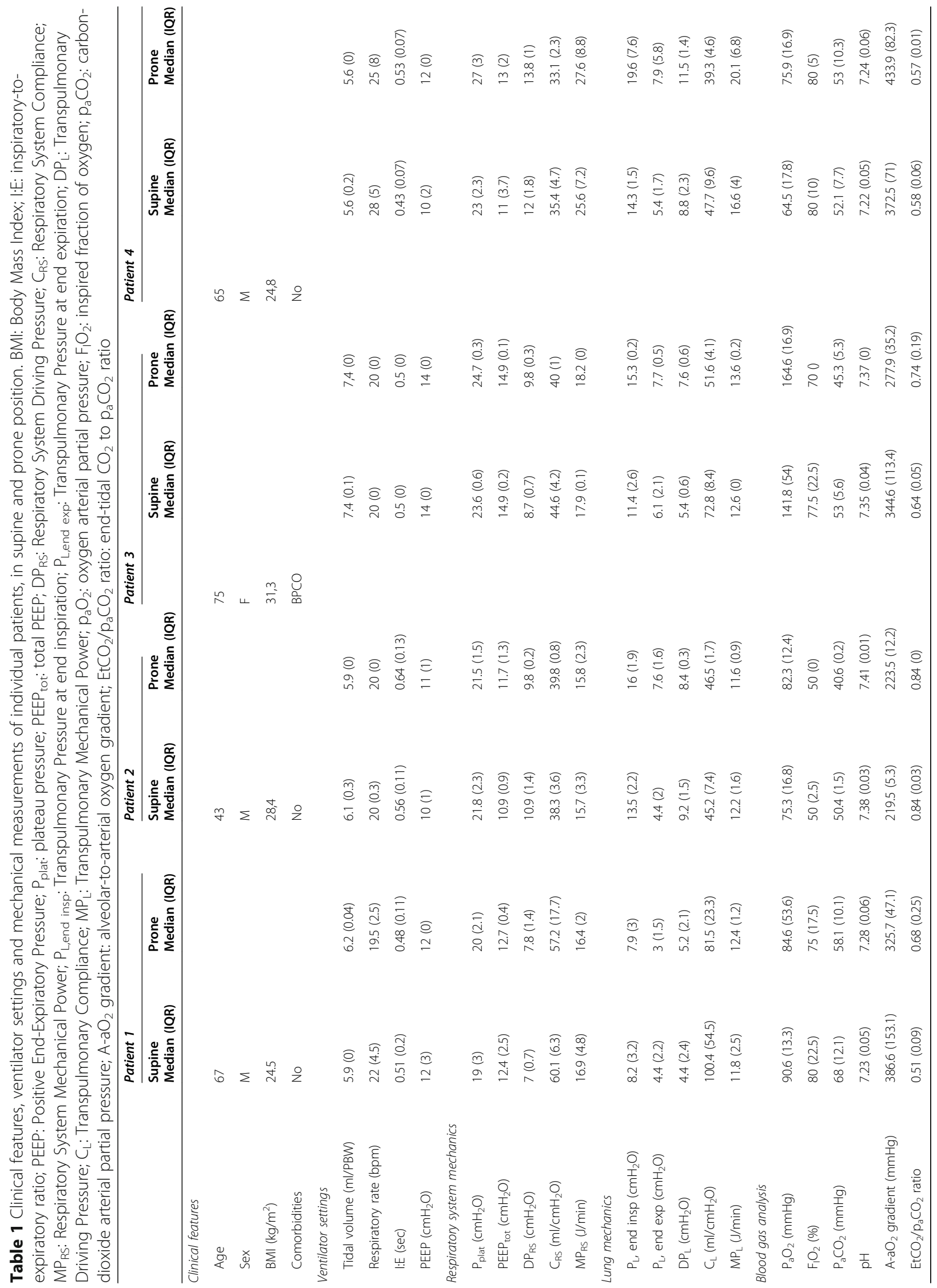


indeed, whereas median lung and respiratory compliance in prone and supine position does not substantially differ, $\mathrm{C}_{\mathrm{RS}}$ and $\mathrm{C}_{\mathrm{L}}$ worsen throughout pronation time $\left(\mathrm{C}_{\mathrm{RS}, \mathrm{END}}\right.$ SUP $56.3 \mathrm{ml} / \mathrm{cmH}_{2} \mathrm{O}$ vs. $\mathrm{C}_{\mathrm{RS}, \mathrm{END}} \mathrm{PR} 41.5 \mathrm{ml} / \mathrm{cmH}_{2} \mathrm{O}-\mathrm{P}$ 0.37; $\mathrm{C}_{\mathrm{L}, \mathrm{END}}$ suP $80.8 \mathrm{ml} / \mathrm{cmH}_{2} \mathrm{O}$ vs. $\mathrm{C}_{\mathrm{L}, \mathrm{END}} \mathrm{PR} 53.2 \mathrm{ml} /$ $\mathrm{cmH}_{2} \mathrm{O}$ - P 0.23; see Fig. 1).

In previous studies on primary ARDS, prone positioning was associated with a decrease of chest wall compliance $\left(C_{C W}\right)$, but did not substantially affect $C_{R S}$ nor $C_{L}$ [9]. In a review published in 2018, Guérin and Mezidi investigated the effect of patient positioning on respiratory mechanics in critical patients under mechanical ventilation. Prone position resulted in an increase of $C_{R S}$ in three of the eight trials analyzed; transpulmonary pressure was measured only in five studies: in two of them, $C_{L}$ increased; in the remaining three studies, $C_{L}$ was unchanged [11]. There are at least two differences between those studies and our work: first of all, time in prone positioning was considerably lower - from few minutes to 2 hours vs. a median of 17 hours; second, all the studies included patients with "classical" ARDS, whose radiological, mechanical and clinical features differ from CoVID-19 pneumonia.
The effect of prone positioning is currently explained by the "sponge model" [12]. According to this model, the inflammatory alveolar edema that characterizes ARDS exerts a hydrostatic pressure that compresses the dependent dorsal lung parenchyma and squeezes out the gas content; prone positioning causes a reversal of this condition: edema tends to compress the ventral lung fields, promoting the reopening of the dorsal areas. This phenomenon accounts for the dubious impact of prone positioning on $C_{R S}$ and $C_{L}$. According to radiological data, in early CoVID-19 pneumonia the edematous component is less represented and it may be assumed that, as the sponge model fails, the pathophysiological basis of the pronation effect will change. The reasons why $C_{L}$ and consequently $C_{R S}$ decrease during prone positioning in CoVID-19 patients have yet to be investigated: a hypothesis could be that pronation carries out a reorganization of incipient lung edema with a resulting increase in lung elastance. CT studies, as well as the application of electric impedance tomography, may help to verify this theory.

The clinical consequence of this pseudo-normal behavior of respiratory mechanics during prone position

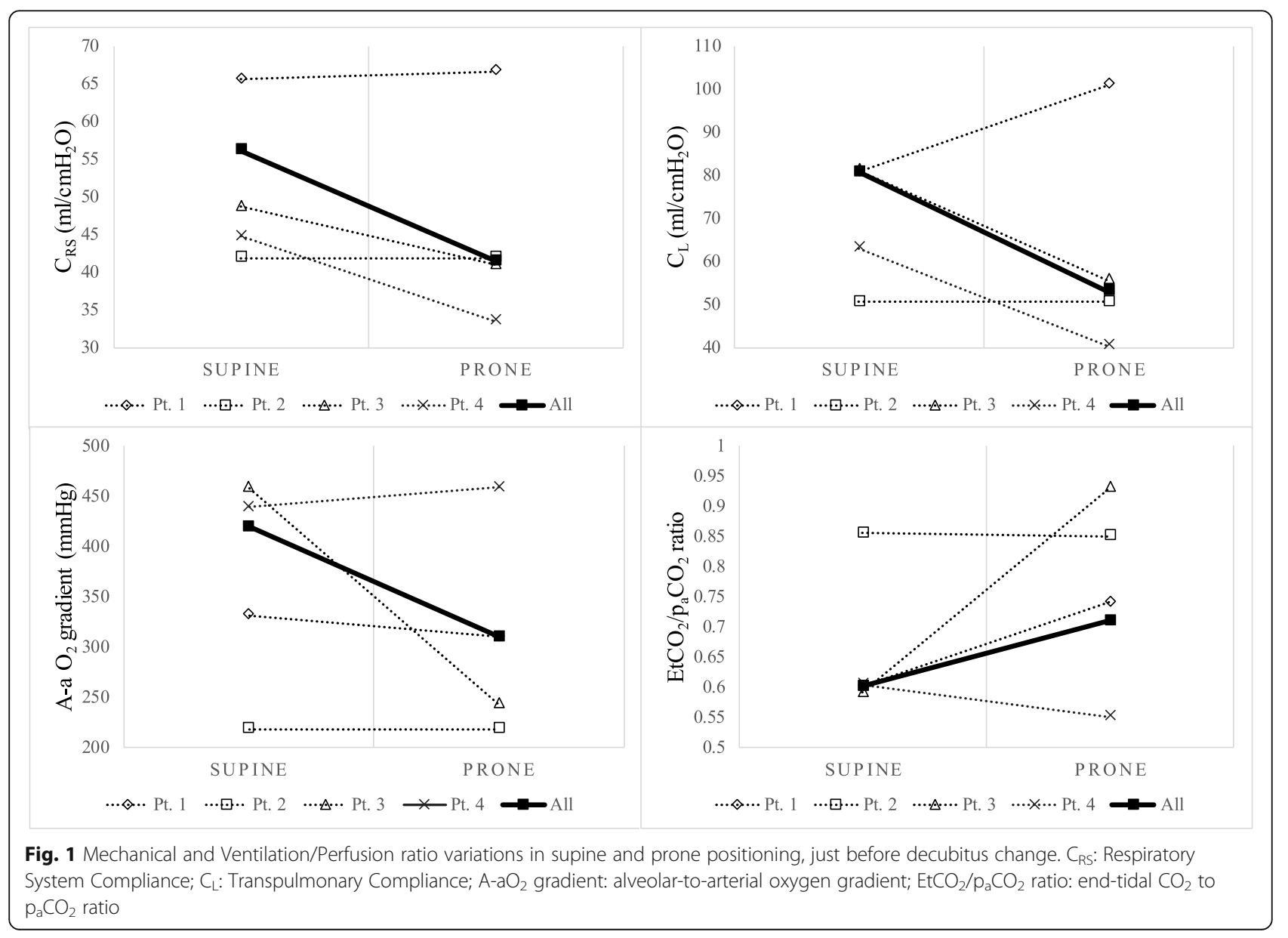


should also be clarified. As expected, we registered a worsening trend both in respiratory system and lung mechanical power $\left(\mathrm{MP}_{\mathrm{RS}, \mathrm{SUP}} 17.4 \mathrm{~J} / \mathrm{min}\right.$ vs. $\mathrm{MP}_{\mathrm{RS}, \mathrm{PR}}$ $18 \mathrm{~J} / \mathrm{min}-\mathrm{P} 0.53$ and $\mathrm{MP}_{\mathrm{L}, \mathrm{SUP}} 12.5 \mathrm{~J} / \mathrm{min}$ vs. $\mathrm{MP}_{\mathrm{L}, \mathrm{PR}}$ $14.1 \mathrm{~J} / \mathrm{min}-\mathrm{P} 0.29$ ), indicating a greater risk of VILI induction with prolonged prone positioning.

Given the small number of enrolled patients this study is meant to be a pilot study. To reach statistical significance a sample size of 14 subject is needed (Power analysis with alpha 0.05 and Power 80\%). Our study lacks the statistical power to verify our findings; as well, we can only hypothesize the reason why we registered those changes in respiratory mechanics. Thus, future studies should aim to the statistical validation of our data and, secondly, to their explanation.

\section{Conclusions}

Our data underline the differences between classical ARDS and type $\mathrm{L}$ pneumonia, characterized by a pseudo-normal lung mechanics that deteriorates during prone positioning. This paper would be a "call for research" in this emerging topic; we firmly believe that understanding the unusual pathophysiology of severe respiratory failure in SARS-CoV-2 infected patients is the key to effectively treating these critically ill patients.

\footnotetext{
Abbreviations

A-aO $\mathrm{O}_{2}$ gradient: Alveolar-to-arterial Oxygen gradient; ARDS: Acute Respiratory Distress Syndrome; $C_{C W}$ : Chest Wall Compliance; $C_{R S}$ : Respiratory System

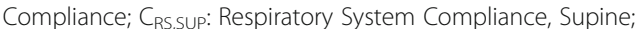

$C_{R S, P R}$ : Respiratory System Compliance, Prone; $C_{L}$ : Transpulmonary Compliance; C L,Sup: Transpulmonary Compliance, Supine:

$C_{L, P R}$ : Transpulmonary Compliance, Prone; CoVID-19: Coronavirus Infectious Disease-19; CT: Computed Tomography; DPRs: Respiratory System Driving Pressure; $\mathrm{DP}_{\mathrm{L}}$ : Transpulmonary Driving Pressure; $\mathrm{EtCO}_{2} / \mathrm{p}_{\mathrm{a}} \mathrm{CO}_{2}$ ratio: end-tida $\mathrm{CO}_{2} / \mathrm{PaCO}_{2}$ ratio; ICU: Intensive Care Unit; $\mathrm{MP}_{\mathrm{RS}}$ : Respiratory System Mechanical Power; $M P_{L}$ : Transpulmonary Mechanical Power; $\mathrm{P}_{\mathrm{a}} \mathrm{CO}_{2}$ : carbon dioxide arterial partial pressure; $P_{\text {AW: }}$ : Airway Pressure; PBW: Predicted Body Weight; $P_{E S}$ : Esophageal Pressure; $P_{L}$ : Transpulmonary pressure; RR: Respiratory Rate; V/Q ratio: Ventilation/Perfusion ratio; VILI: VentilationInduced Lung Injury; $V_{\mathrm{t}}$ : Tidal Volume
}

\section{Acknowledgements}

Not applicable

\section{Authors' contributions}

LV: study design, data collection, writing of the manuscript; ER: study design, writing of the manuscript; MB: study design, data collection; EG: data collection; AC: data collection; LB: data collection; DPS: data collection; GS: data collection; GB: data collection; LM: data collection; VA: study design, writing of the manuscript. All authors read and approved the final manuscript.

\section{Funding}

Not applicable.

\section{Availability of data and materials}

The datasets used and/or analysed during the current study are available from the corresponding author on reasonable request.

Ethics approval and consent to participate

- this study was approved by the Ethical Committee of AUSL Romagna.

\section{Consent for publication}

Not applicable.

\section{Competing interests}

The authors declare that they have no competing interests.

\section{Author details}

'U.O. Anestesia e Rianimazione, Ospedale "M. Bufalini" Hospital, 286, Viale Ghirotti, Cesena, Italy. ${ }^{2}$ University of Messina, Messina, Italy.

Received: 15 September 2020 Accepted: 11 November 2020 Published online: 21 December 2020

\section{References}

1. Gattinoni L, Coppola S, Cressoni M, Busana M, Rossi S, Chiumello D. COVID19 Does Not Lead to a "Typical" Acute Respiratory Distress Syndrome. Am J Respir Crit Care Med. 2020;15(10):1299-300. 201.

2. Alhazzani W, Møller MH, Arabi YM, Loeb M, Gong MN, Fan E, et al. Surviving Sepsis Campaign: guidelines on the management of critically ill adults with Coronavirus Disease 2019 (COVID-19). Intensive Care Med. 2020;46(5):854-87.

3. Gattinoni L, Marini JJ, Collino F, Maiolo G, Rapetti F, Tonetti T, et al. The future of mechanical ventilation: lessons from the present and the past. Crit Care. 2017;21(1):183.

4. Gattinoni L, Chiumello D, Caironi P. Busana M, Romitti F, Brazzi L, et al. COVID-19 pneumonia: different respiratory treatments for different phenotypes? Intensive Care Med. 2020:14:1-4.

5. Gattinoni L, Chiumello D, Rossi S. COVID-19 pneumonia: ARDS or not? Version 2. Crit Care. 2020;16(1):154. 24(

6. Grieco DL, Chen L, Brochard L. Transpulmonary pressure: importance and limits. Ann Transl Med. 2017:5(14):285

7. Serpa Neto A, Deliberato RO, Johnson AEW, Bos LD, Amorim P, Pereira SM, et al. Mechanical power of ventilation is associated with mortality in critically ill patients: an analysis of patients in two observational cohorts. Intensive Care Med. 2018;44(11):1914-22.

8. Cressoni M, Gotti M, Chiurazzi C, Massari D, Algieri I, Amini M, et al. Mechanical Power and Development of Ventilator-induced Lung Injury. Anesthesiology. 2016:124(5):1100-8.

9. Koulouras V, Papathanakos G, Papathanasiou A, Nakos G. Efficacy of prone position in acute respiratory distress syndrome patients: A pathophysiologybased review. World J Crit Care Med. 2016;4(2):121-36. 5(.

10. Tobin MJ. Basing Respiratory Management of Coronavirus on Physiological Principles. Am J Respir Crit Care Med. 2020. DOl:https://doi.org/10.1164/ rccm.202004-1076ED.

11. Mezidi $\mathrm{M}$, Guérin C. Effects of patient positioning on respiratory mechanics in mechanically ventilated ICU patients. Ann Transl Med. 2018;6(19):384. DOI: https://doi.org/10.21037/atm.2018.05.50. PMID: 30460258; PMCID: PMC6212360

12. Bone RC. The ARDS lung. New insights from computed tomography. JAMA. 1993 Apr 28;269(16):2134-5. doi: https://doi.org/10.1001/jama.269.16.2134. PMID: 8468771

\section{Publisher's Note}

Springer Nature remains neutral with regard to jurisdictional claims in published maps and institutional affiliations.
Ready to submit your research? Choose BMC and benefit from:
- fast, convenient online submission
- thorough peer review by experienced researchers in your field
- rapid publication on acceptance
- support for research data, including large and complex data types
- gold Open Access which fosters wider collaboration and increased citations
- maximum visibility for your research: over $100 \mathrm{M}$ website views per year
At $\mathrm{BMC}$, research is always in progress.
Learn more biomedcentral.com/submission 